\title{
Perceived temperature in the course of climate change: an analysis of global heat index from 1979 to 2013
}

\author{
D. Lee ${ }^{1}$ and T. Brenner ${ }^{2}$ \\ ${ }^{1}$ German Meteorological Service, Frankfurterstr. 135, 63067 Offenbach, Germany \\ ${ }^{2}$ University of Marburg, Deutschhausstr. 10, 35032 Marburg, Germany \\ Correspondence to: D. Lee (daniel.lee@dwd.de) \\ Received: 27 December 2014 - Published in Earth Syst. Sci. Data Discuss.: 19 March 2015 \\ Revised: 21 July 2015 - Accepted: 22 July 2015 - Published: 5 August 2015
}

\begin{abstract}
The increase in global mean temperatures resulting from climate change has wide reaching consequences for the earth's ecosystems and other natural systems. Many studies have been devoted to evaluating the distribution and effects of these changes. We go a step further and propose the use of the heat index, a measure of the temperature as perceived by humans, to evaluate global changes. The heat index, which is computed from temperature and relative humidity, is more important than temperature for the health of humans and animals. Even in cases where the heat index does not reach dangerous levels from a health perspective, it has been shown to be an important factor in worker productivity and thus in economic productivity.

We compute the heat index from dew point temperature and absolute temperature $2 \mathrm{~m}$ above ground from the ERA-Interim reanalysis data set for the years 1979-2013. The described data set provides global heat index aggregated to daily minima, means and maxima per day (doi:10.1594/PANGAEA.841057). This paper examines these data, as well as showing aggregations to monthly and yearly values. Furthermore, the data are spatially aggregated to the level of countries after being weighted by population density in order to facilitate the analysis of its impact on human health and productivity. The resulting data deliver insights into the spatiotemporal development of near-ground heat index during the course of the past three decades. It is shown that the impact of changing heat index is unevenly distributed through space and time, affecting some areas differently than others. The data can serve as a basis for evaluating and understanding the evolution of heat index in the course of climate change, as well as its impact on human health and productivity.
\end{abstract}

\section{Introduction}

The essential cause of climate change is the additional entrapment of thermal energy in the earth's many natural systems through carbon dioxide from anthropogenic sources. The speed at which this is occurring is, on climatological and geological timescales, extremely rapid, often requiring faster adaptation than would be expected under normal circumstances.

This additional heat energy has manifold consequences, many of them indirect. All of them, in one way or another, affect humans. For example, additional heat modifies the earth's water household, reducing agricultural yields and in this way affecting human health and well-being (Calzadilla et al., 2010). More directly, additional heat load has been shown to affect the economy by reducing worker productivity through requiring workers to work more slowly and take more breaks (Kjellstrom et al., 2009). Extreme heat can have serious health consequences, especially among the sick and the elderly. In the last decade, more than 10000 deaths in a single month in France were directly attributed to a heat wave (Poumadère et al., 2005). This list could easily be expanded to include other events and regions, and several studies have shown not only that extreme heat events can be expected with higher frequency and intensity but also that heat load in general should increase in the future (Beniston, 2004; Schär et al., 2004; Intergovernmental Panel on Climate Change, 2014). 
Many studies have analyzed the effects of climate change on global temperatures and their distribution in space and time (e.g., Vose et al., 2005; Diffenbaugh and Ashfaq, 2010; Diffenbaugh and Scherer, 2011; Alexander and Arblaster, 2009; Meehl et al., 2009; Smith et al., 2005; Sherwood et al., 2008). They show that changes in the earth's thermal energy household affect the flow of both latent and sensible heat and are thus the most directly relevant for human physiology. The body rids itself of thermal energy partially through the evaporation of sweat. This process becomes less efficient with higher humidity. For this reason, most metrics that measure heat exposure take both temperature and humidity into account. For example, the wet-bulb globe temperature (WBGT), which incorporates the effect of temperature, humidity, wind speed and radiation into a metric for heat stress in humans, has been used in several health and safety standards measure heat loads and prevent heat illnesses (e.g., International Organization for Standardization, 2010; National Institute for Occupational Safety and Health, 1986). Although WBGT is an accurate metric for heat load on humans, the number of variables needed to compute it hinder its applicability for regional- or global-scale applications. Other examples include, among others, the Klima-Michel model for apparent temperature, which uses not only temperature, wind speed and air moisture but also activity level and clothing to determine the apparent temperature for an average person (Jendritzky et al., 1990). In the field of meteorology, a much more common metric is apparent temperature, measured using the heat index (Anderson et al., 2013). This metric has seen wider adoption in the health and meteorological communities due to its dependence solely on humidity and temperature (e.g., Perry et al., 2011; Kysely and Kim, 2009; El Morjani et al., 2007; Burkart et al., 2011; Basara et al., 2010).

We present a new data set of globally gridded heat index values computed from reanalysis results for the years 19792013. These values are aggregated on several temporal and spatial scales. The data are presented in the context of global climate change and its direct effects on human health. We several temporal and spatial scales. Furthermore, we describe the effects of climate change on the global distribution of heat index and investigate these effects for different countries through the study's time period. The data are available for further use by the scientific community (Lee, 2014). It is our hope that these data can serve as a basis for further studies to evaluate and understand changes in heat index over the course of climate change and how it impacts different areas of human society.

\section{Material and methods}

\subsection{Data source}

High-quality, consistent data measured at the same place over climate-scale time periods are extremely difficult to obtain.
For this reason, we use reanalysis data in order to create the data set on heat index.

Reanalysis data are not an equivalent to observation data and should be used carefully (Thorne and Vose, 2010). Nonetheless, for our purpose, reanalysis data seem to be the most appropriate choice. A priority is to produce spatially and temporally continuous data of a consistent quality for the entire globe over a long period of time. In addition, as many high-quality observations should be incorporated into the data as possible, without introducing anomalous signals into the data, for example through changes in observation techniques and shifts in observation locations.

The ERA-Interim reanalysis by ECMWF is well suited for this task. It uses the same data assimilation system and dynamic modeling core over a long period of time - from 1979 extended up until the present. The model used to produce the reanalysis, the ECMWF's Integrated Forecast System (IFS), uses three fully coupled components for atmosphere, land surface and ocean waves. This improves accuracy especially for areas surrounded mostly by ocean. Because the model was used to produce a reanalysis, which did not have to be published in a time critical fashion, observations from all over the globe could be assimilated, even if they were only available after a normal forecast model's cutoff time. These observations can be quality-controlled before being assimilated into the model. Using a model rather than, for example, a simpler interpolation approach makes it possible for the model to propagate information obtained through observations through variable domains, space and time (Dee et al., 2011). All of these criteria made ERA-Interim an intuitive choice as a basis for our study (Dee et al., 2011).

The ERA-Interim reanalysis used four assimilation cycles per day, at 00:00, 06:00, 12:00 and 18:00 UTC. The original data were produced on a reduced Gaussian grid with approximately uniform spacing for surface fields of $79 \mathrm{~km}$ (Berrisford et al., 2009).

We use data from the entire available time period of 19792013. The data were downloaded after interpolation from the Gaussian onto a regular $0.75^{\circ} \times 0.75^{\circ}$ latitude-longitude grid to ease processing in various GISs. Two variables were downloaded: air temperature and dew point temperature, both at $2 \mathrm{~m}$ height above ground.

\subsection{Computing gridded heat index}

Heat index has been computed using a variety of algorithms in different studies. We chose the currently operational method used by the National Weather Service (2014a), which was developed by Rothfusz (1990) based on work by Steadman (1979), because it is used widely in the operational production of weather warnings in real-life situations and demonstrates the best agreement among heat index algorithms with the original equations (Anderson et al., 2013). All calculation was done using GRASS GIS (GRASS Development Team, 2012). 
The chosen algorithm uses relative humidity and temperature in ${ }^{\circ} \mathrm{F}$ at $2 \mathrm{~m}$ above ground as input. While temperature is given in the ERA-Interim reanalysis data, relative humidity had to be calculated. Of the many possible ways to compute relative humidity from dew point temperature (see, for example, Lawrence, 2005), we decided to follow the methodology of the National Weather Service (Murphy, 2006) for the sake of consistency with the method of computing heat index. It is computed as follows:

$\mathrm{RH}=\left(\frac{112-0.1 T+T_{\mathrm{d}}}{112+0.9 T}\right)^{8}$,

with RH as relative humidity, $T$ as temperature in ${ }^{\circ} \mathrm{C}$ and $T_{\mathrm{d}}$ as dew point temperature in ${ }^{\circ} \mathrm{C}$.

Heat index was computed using an algorithm beginning with a simple approximation:

$\mathrm{HI}=\frac{T+61.0+((T-68.0) \cdot 1.2)+(\mathrm{RH} \cdot 0.094)}{2}$,

where $\mathrm{HI}$ is heat index in ${ }^{\circ} \mathrm{F}, T$ the temperature in ${ }^{\circ} \mathrm{F}$ and $\mathrm{RH}$ the relative humidity.

If $\mathrm{HI}$ is $<80^{\circ} \mathrm{F}$, this approximation is kept as the final result. Otherwise, it must be computed with a more precise regression:

$$
\begin{aligned}
\mathrm{HI}= & -42.379+2.04901523 \cdot T+10.14333127 \\
& \cdot \mathrm{RH}-0.22475541 \cdot T \cdot \mathrm{RH} \\
& -0.00683783 \cdot T^{2}-0.05481717 \cdot \mathrm{RH}^{2} \\
& +0.00122874 \cdot T^{2} \cdot \mathrm{RH}+0.00085282 \cdot T \cdot \mathrm{RH}^{2} \\
& -0.00000199 \cdot T^{2} \cdot \mathrm{RH}^{2}+\text { adjustment, }
\end{aligned}
$$

with the adjustment conditionally given by

$$
\text { adjustment }=\left\{\begin{array}{ll}
\frac{13-\mathrm{RH}}{4} \cdot \sqrt{\frac{17-|T-95|}{17}} & \text { if } \mathrm{RH}<0.13 \text { and } 80<T<112 \\
\frac{\mathrm{RH}-85}{10} \cdot \frac{87-T}{5} & \text { if } \mathrm{RH}>0.85 \text { and } 80<T<87 \\
0 & \text { else }
\end{array} .\right.
$$

\subsection{Limitations of the approach}

It should be noted that the heat index, which was created for the purpose of measuring physiological stress due to high heat loads, is not adapted for measuring stress due to coldness. Also, above a certain level the heat index is oversaturated, so that no additional information can be gained from it. For this reason, we rounded extreme heat index values into the range of $40-140^{\circ} \mathrm{F}$ in our visualizations. This corresponds with the lower bounds of the heat index equation (Anderson et al., 2013) and the rough upper bounds of danger levels derived from heat index (National Weather Service, 2014b). The published raw data, however, are not rounded, so that users can decide whether or not they wish to reduce its value range (Lee, 2014).

\subsection{Temporal and spatial aggregation}

The primary reason that heat index is so relevant in the context of climate change is its direct and indirect effects on human health and the anthropogenic systems connected to it. Thus, we expect that our data on the heat index can and will be used in many further studies, in which they will be connected to other data.

The heat index is calculated for each grid point and for each point in time for which the ERA-Interim reanalysis is available. However, using the calculated heat index in further studies usually implies that data on a daily or even monthly or yearly basis are necessary. Therefore, we aggregated the heat index to daily levels. For each day, the four assimilations were combined in order to produce gridded daily minima, means and maxima. We consider this a good approximation of the nighttime heat index, which represents the daily minimum in most cases; the actual local mean heat index over the course of the day; and the daily midday heat index, which is the maximum in most cases. In addition to producing these daily aggregates, the daily metrics were aggregated to monthly and yearly temporal levels.

In addition to the temporal aggregate, the combination with other data will also make a spatial aggregation necessary in many studies. Other data are often given on a regional or national level. Therefore, we also examine the heat index on the level of countries. For studying the effect on humans and human activities, the heat index in populated areas is especially relevant, as dangerous heat exposure in areas where no people are affected is at most tangentially connected to human well-being.

The Global Rural-Urban Mapping Project (GRUMP) (Center for International Earth Science Information Network - CIESIN - Columbia University; International Food Policy Research Institute - IFPRI; The World Bank; Centro Internacional de Agricultura Tropical - CIAT, 2011) provides high-quality gridded population data. The data set consists of estimates of human population for the years 1990, 1995 and 2000 on a 30 arc-second grid (meaning a horizontal resolution of approximately $1 \mathrm{~km}$ ) for the entire globe. GRUMP is based on work originally done for the Gridded Population of the World (GPW) data set (Center for International Earth Science Information Network - CIESIN - Columbia University; International Food Policy Research Institute - IFPRI; The World Bank; Centro Internacional de Agricultura Tropical - CIAT, 2004), which was produced by resampling census and survey data for administrative units onto a regular grid. The population was temporally interpolated between sampling points to the above-mentioned snapshot years. GRUMP refined the original data by identifying urban areas with the help of administrative data and nighttime satellite data. Population was then redistributed inside administrative areas to the respective urban and rural areas in order to match the proportion of urban-rural population described by data from the United Nations (Balk et al., 2010). 
Because of the large number of changes in administrative boundaries and population distribution in the years following the dissolution of the Soviet Union in 1991, the authors of GRUMP were often forced to combine heterogeneous data sources into their results (Balk and Yetman, 2004). Although this was done with a high degree of care and in-depth knowledge of each individual case, the uncertainties that this produced prompted us to consider the estimates from 1990 to be the best compromise between quality, consistency and the required accuracy for our analyses. Thus, we only use the GRUMP data for 1990 to aggregate our data to the national level.

Furthermore, for the sake of consistency, we aggregated the population data into current political boundaries (Patterson and Kelso, 2014), rather than adjusting the data to accommodate the modification, addition or dissolution of national borders over time. Therefore, all statements about changes in the climate of given countries in this study should be interpreted as referring to the geographic areas currently officially occupied by the country in question, rather than the possibly dynamic geographic area occupied by the country over the study period.

The following steps were used to aggregate our data to the country level. First, the heat index data for the areas covered by each country were rasterized onto the same coordinate system as the GRUMP data. This made it possible to discretely sum the population inside each country according to the GRUMP estimates. Per-grid-point population weights were produced by calculating the proportion of population within that country that contained the grid point in question, as follows:

$p_{\text {weight }}=\frac{p_{\text {total }}}{p_{\text {count }}}$

where $p_{\text {weight }}$ is the cell's population weight inside the country, $p_{\text {total }}$ the country's total population and $p_{\text {count }}$ the population count for the grid point.

The per-country weighted mean heat index was then computed as follows:

$\mathrm{HI}_{\text {weight }}=\sum p_{\text {weight }} \cdot \mathrm{HI}$.

Weighted means were produced for each country with available data and each temporal aggregation level, as outlined in Sect. 2.4.

\section{Application: heat index and global climate change}

As mentioned above, we expect that the heat index as it is calculated here can and will be used in many future studies. To give some first impression we discuss the change of the heat index between the time periods 1979 and 1999 and 2000 and 2013. Although neither of these periods represents a typical 30-year climate period, this was considered a good compromise which placed the bulk of the data in the 1970-1999 and
Table 1. Heat index danger levels according to National Weather Service (2014b).

\begin{tabular}{ll}
\hline${ }^{\circ} \mathrm{F}$ & Danger level \\
\hline$>80$ & Caution \\
$>91$ & Extreme caution \\
$>103.5$ & Danger \\
$>126$ & Extreme danger \\
\hline
\end{tabular}

2000-2029 climate periods while splitting the data into temporal chunks of similar lengths. All data visualization is done using ggplot2 (Wickham, 2009).

\subsection{Global heat index}

Figure 1 shows the heat index metrics for the entire globe on a typical day in summer in the Northern Hemisphere. Dangerous heat index levels can be seen both in the daytime maximum, as well as during the night in hot, moist regions near the Equator. The diurnal cycle is especially high for hot and moist regions, high for dry areas in which the temperature fluctuates highly in the course of the diurnal cycle, and low in drier areas with relatively small diurnal temperature cycles.

The change between both reference periods is shown in Fig. 2. The maximum heat index shows large changes in both directions for single grid points. This is due to the fact that the maximum heat index for each entire reference period stems from single, significant events that are highly specific in both time and space. This causes spatial shifts in the occurrence of extreme heat index events to produce large deviances between reference periods, similar to the doublepenalty problem encountered when computing skill scores for high-resolution forecast models (Mass et al., 2002). Mean and minimum heat indices increase almost across the globe between both reference periods, with the most notable differences in minimum heat index over continents in the Northern Hemisphere.

An evaluation of the change in monthly mean heat index across the globe for both reference periods, as shown in Fig. 3, offers a glimpse into the temporal distribution of heat index changes in the course of the year. The monthly means of heat index clearly increase across the globe, most visibly at higher latitudes.

One of the most important applications of our data is the evaluation of danger due to high heat loads. We classified danger due to high heat index according to the criteria outlined in Table 1.

For each reference period and each of the classification criteria shown above we calculate the probability that the peak heat index of each day exceeds the threshold for extreme danger in each month. Then, we compare the exceedance likelihood between the two reference periods. The results, shown in Fig. 4, demonstrate that the likelihood of heat index values 

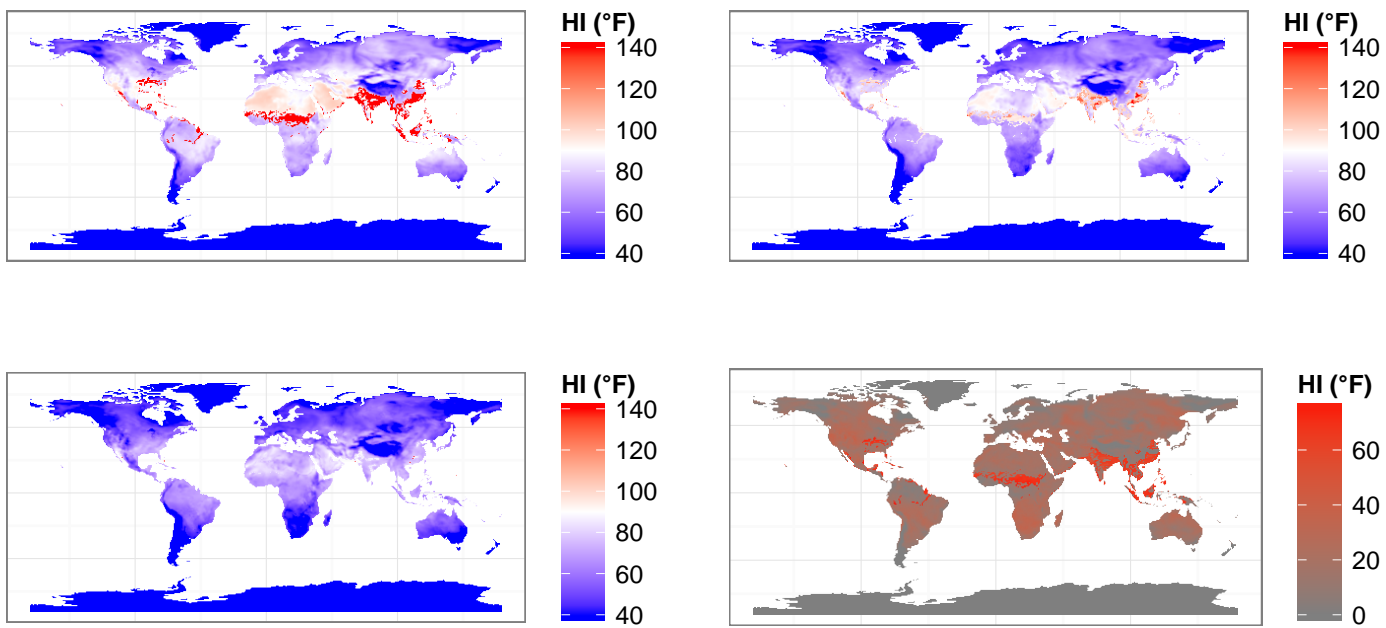

Figure 1. Typical heat index for an exemplary day (2 June 1996). Upper left: maximum heat index; lower left: minimum heat index; upper right: mean heat index; lower right: diel range of heat index.
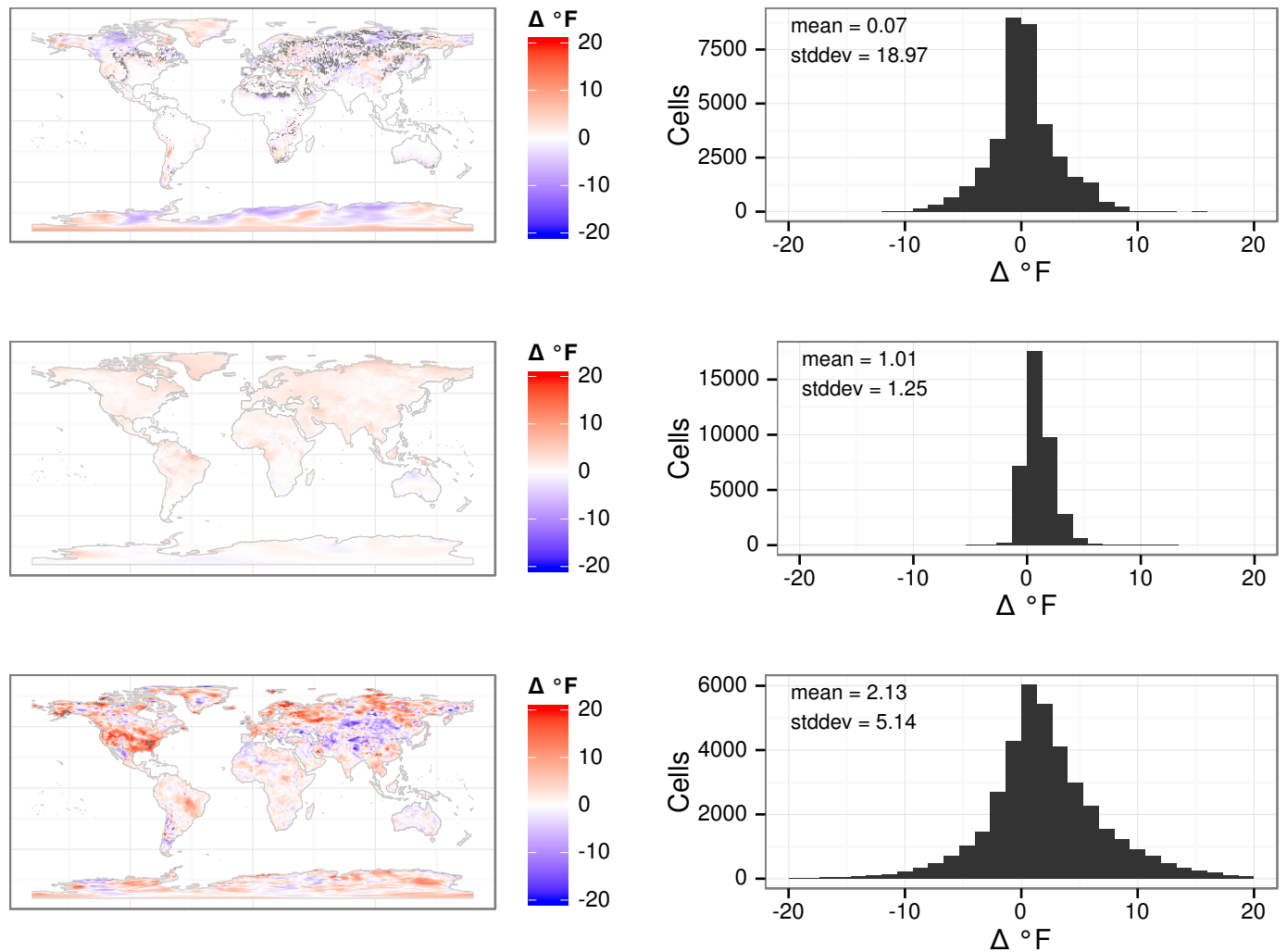

Figure 2. Differences between yearly temporal statistics for each reference period (1979-1999, 2000-2013). The left column shows, from top to bottom, the differences in maximum, mean and minimum heat index for the entire year for the entire globe. The right column shows the frequencies of heat index changes worldwide in number of cells for each aggregate statistic. Continents are added for orientation (South, 2011; Bivand and Rundel, 2014).

reaching levels that indicate "extreme danger" has increased worldwide in every month. South America during southern summer and the Gulf of Mexico in northern summer had especially large increases in likelihood of extreme danger.
West Africa also had increased likelihood of dangerous heat index levels the year round, as did northern Eurasia for most months. Most parts of Asia, especially northern Asia, showed increases in heat index throughout most of the year. Two no- 

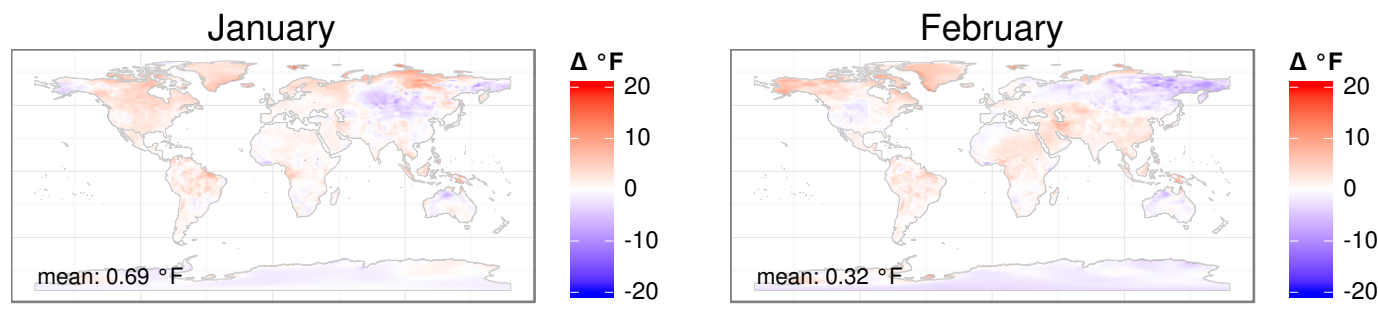

March

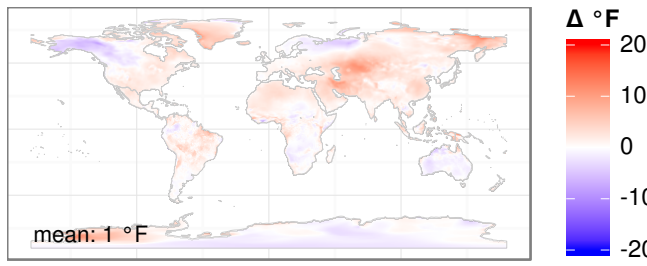

April

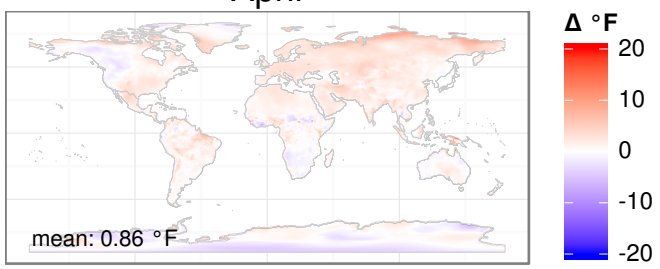

May
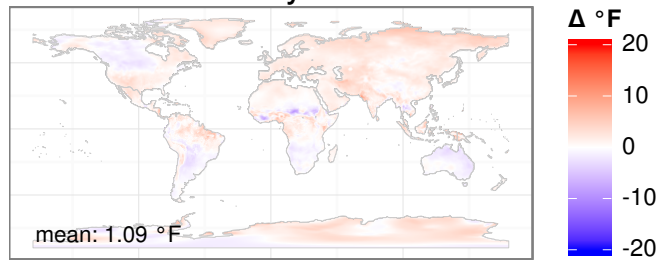

June
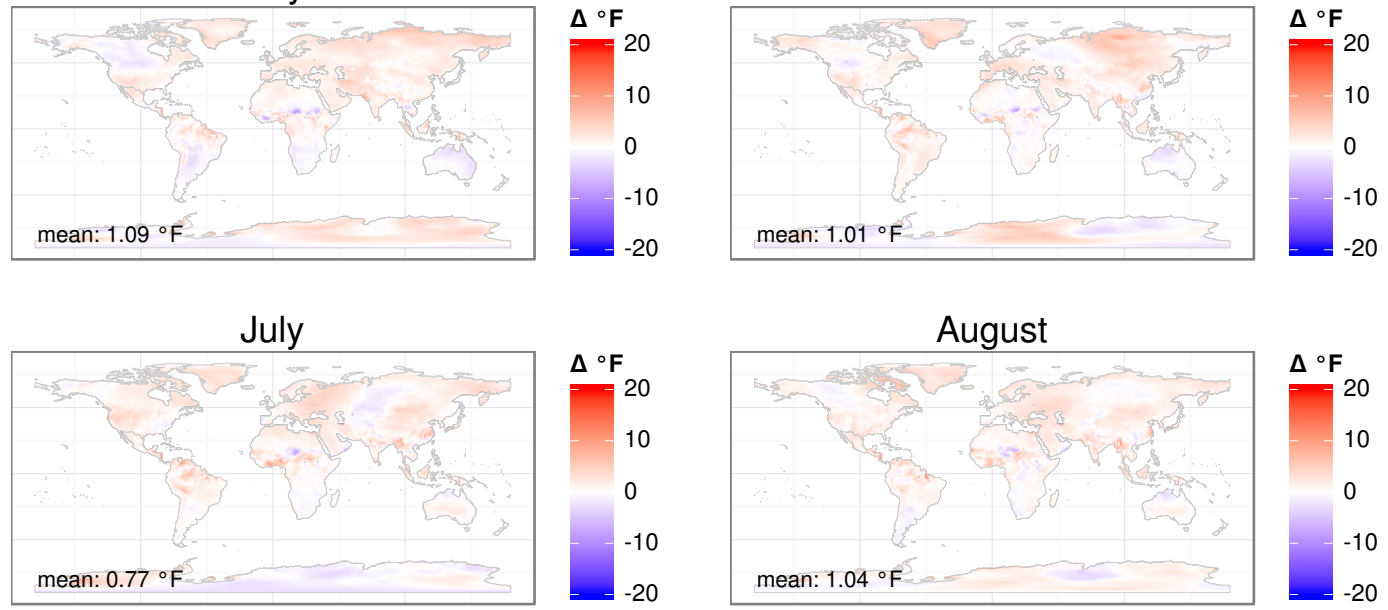

August

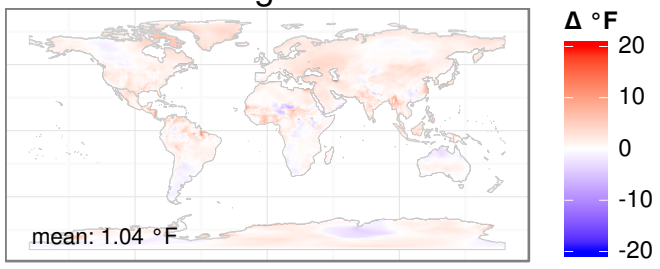

\section{September}
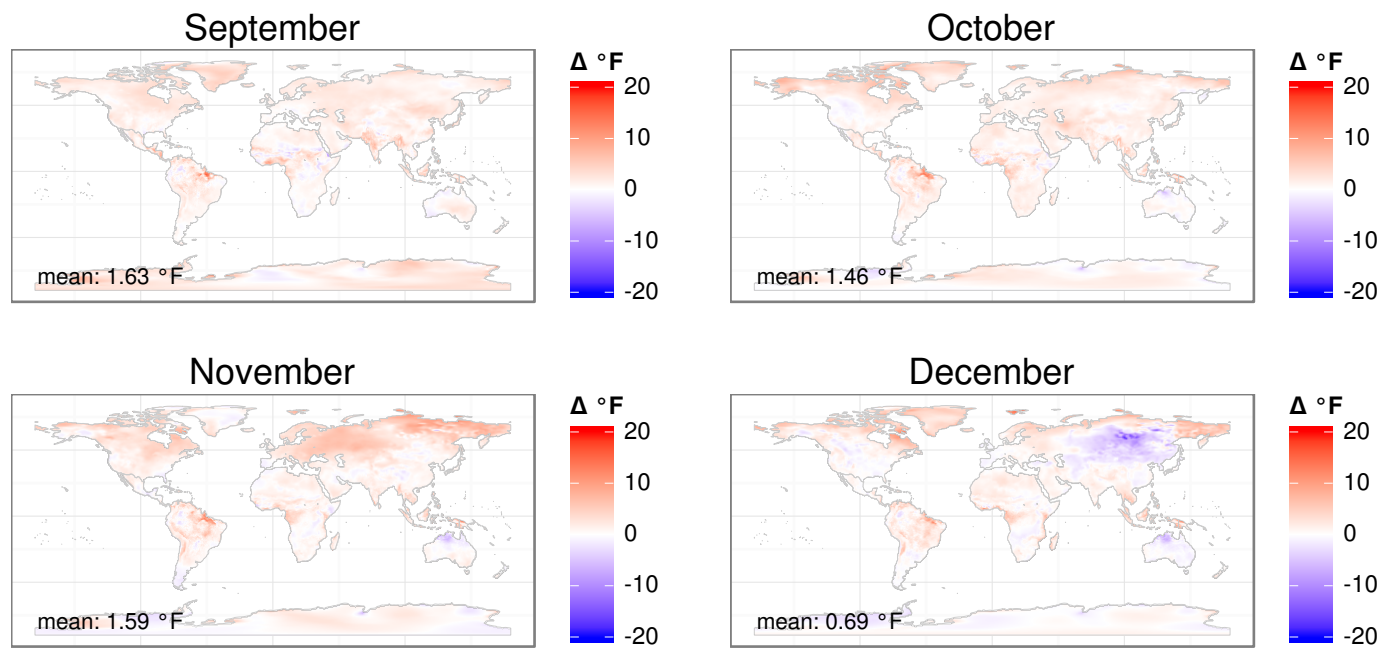

Figure 3. Changes between both reference periods (1979-1999, 2000-2013) in monthly mean heat index. The inset numbers refer to the mean increase in heat index for the month in question between both reference periods. Continents are added for orientation (South, 2011; Bivand and Rundel, 2014). 

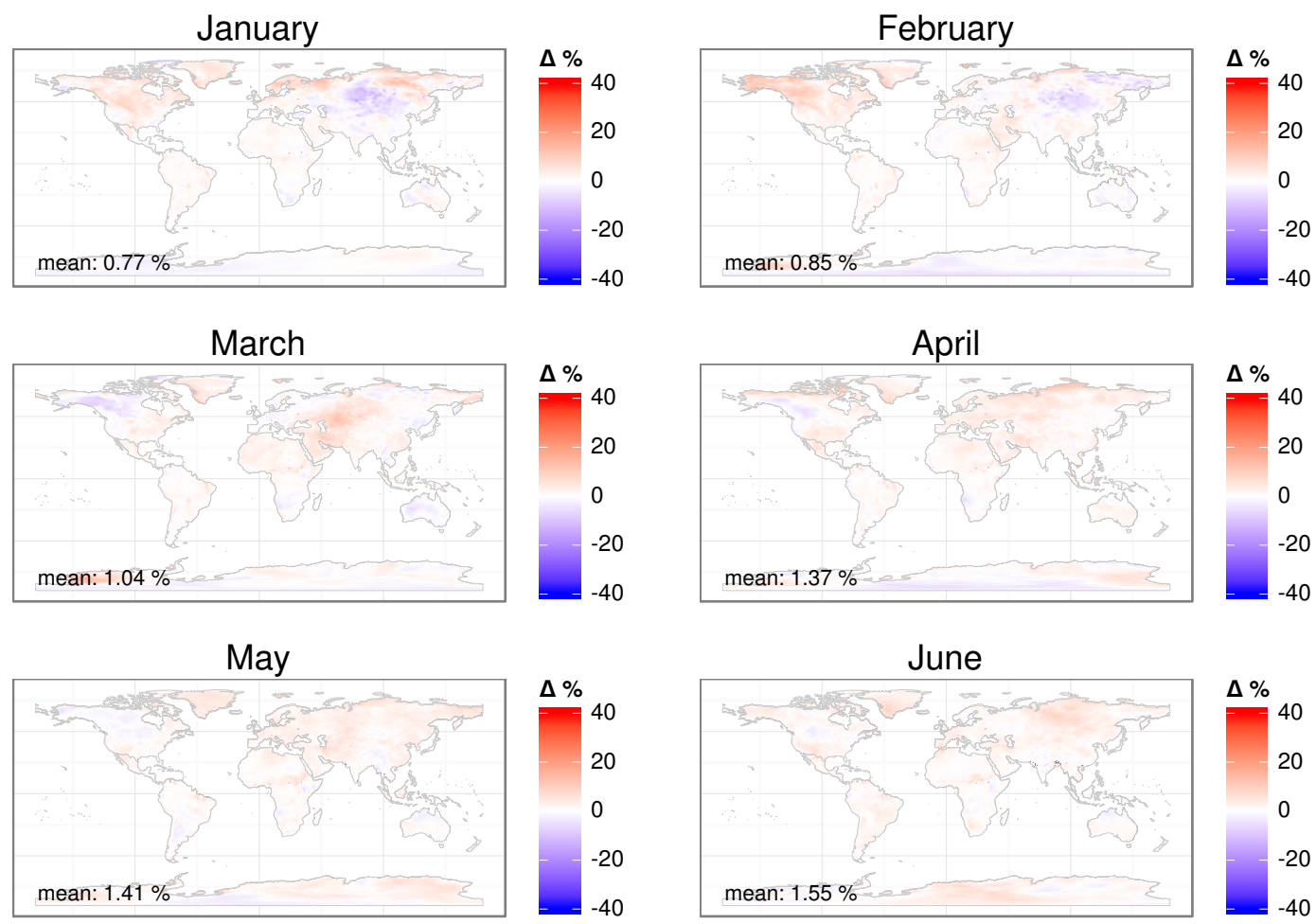

July

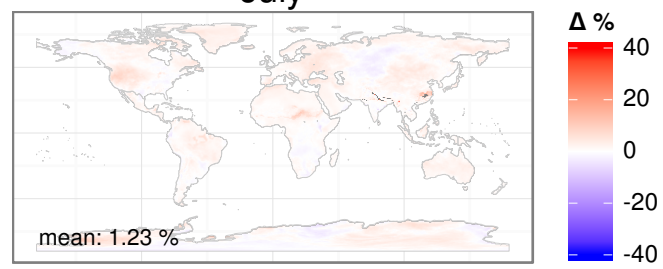

August
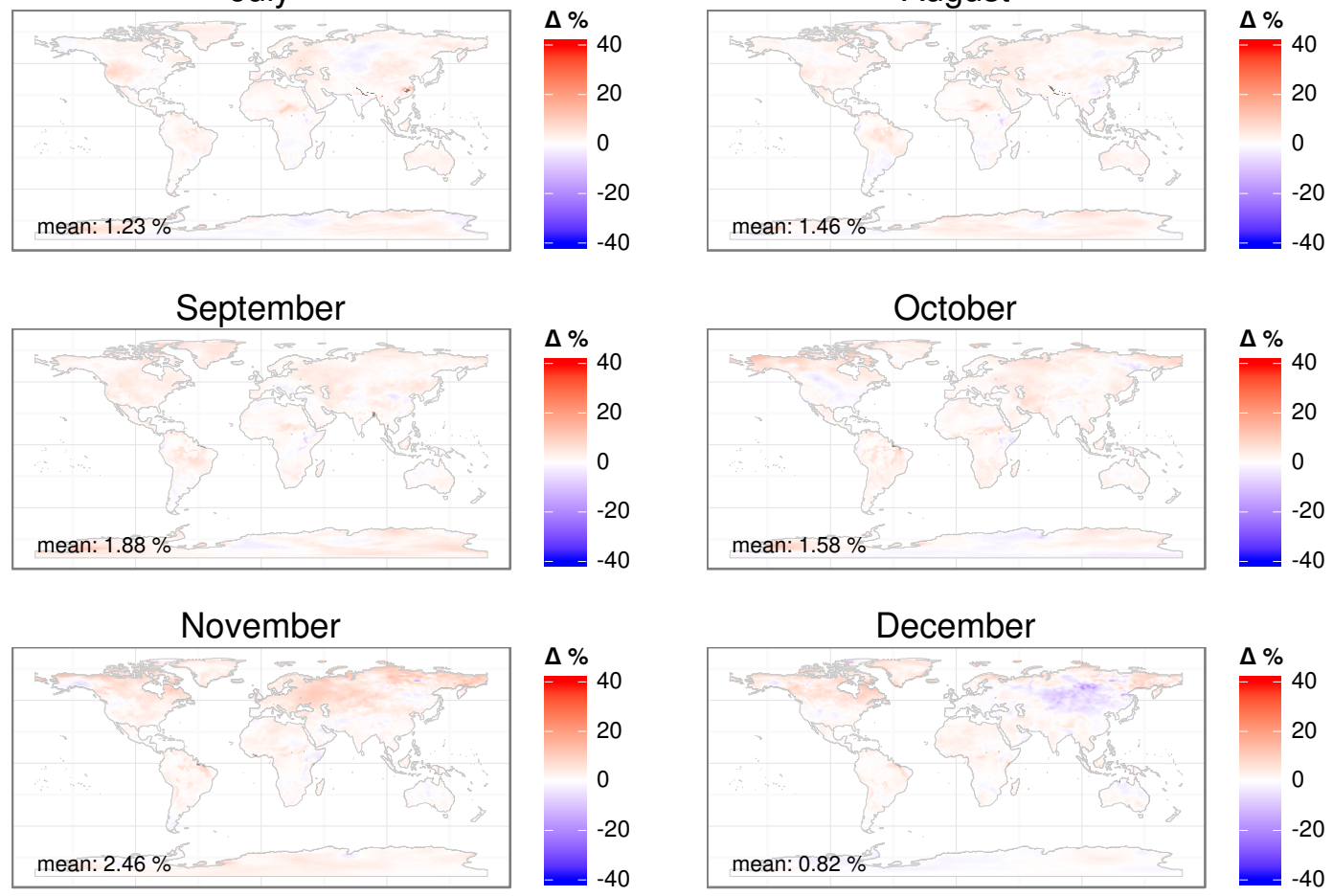

Figure 4. Change in the probability that the maximum heat index will exceed the threshold for "extreme danger" for a given day in each month in 2000-2013 compared to 1979-1999 (National Weather Service, 2014b). Continents are added for orientation (South, 2011; Bivand and Rundel, 2014). 
table exceptions are northern Eurasia and Alaska, which both showed decreases in heat index during northern winter.

\subsection{Classifying countries according to heat index}

Another interesting application of the new data set is the classification of countries according to their heat index climatologies. We use the population-weighted heat index minima, means and maxima in each month and apply an iterative $k$ means cluster identification (Hartigan and Wong, 1979), implemented in the statistical software R (R Core Team, 2014). After each iteration, the sum of squared distance between points in each cluster was examined in order to determine the point at which additional clusters no longer produced useful information (Everitt and Hothorn, 2010, p. 251).

The clustering is applied to both reference periods: eight clusters are created. This number of clusters matched both reference periods well - more clusters did not seem to produce any substantial gains, whereas fewer clusters would have meant a larger sum of squared distance between points inside individual clusters.

The clusters were examined using ordination plots based on the methods by Oksanen et al. (2014). The clusters created by the data for each reference period are similar, but not identical. The changes between both reference periods are shown more clearly in Fig. 5. Most changes are in Africa, southern Europe and Asia. A first visual analysis indicates that subtropical heat index climates have expanded away from the Equator and toward the poles. Especially cool, dry or humid areas retain their climatology across both reference periods.

\section{Conclusions}

In this paper, we introduce a new data set containing gridded heat index values $2 \mathrm{~m}$ above ground for the entire globe at 00:00, 06:00, 12:00 and 18:00 UTC of each day for the years 1979-2013. Due to the widespread use of heat index as an indicator for dangers to human health caused by heat loads, we believe that these data will be of great use in future studies concerning heat stress in the course of climate change. Our data set is new in the sense that it makes heat index values available on a high spatiotemporal resolution and on a continuous grid for the entire planet. We show its potential for further studies by performing some initial, straightforward analyses that provide a first glimpse into the data.

It is shown that, for the two periods chosen for our study (1979-1999, 2000-2013), the distribution of heat index across the globe has changed. The worldwide mean heat index has risen, both for the entire year and for each month. The likelihood of daytime heat index values that indicate "extreme danger" has also increased across the globe since the 20th century. This analysis is meant as an example usage of these data and could be repeated for different thresholds, with a finer quantile resolution, or focused on more specific geo-
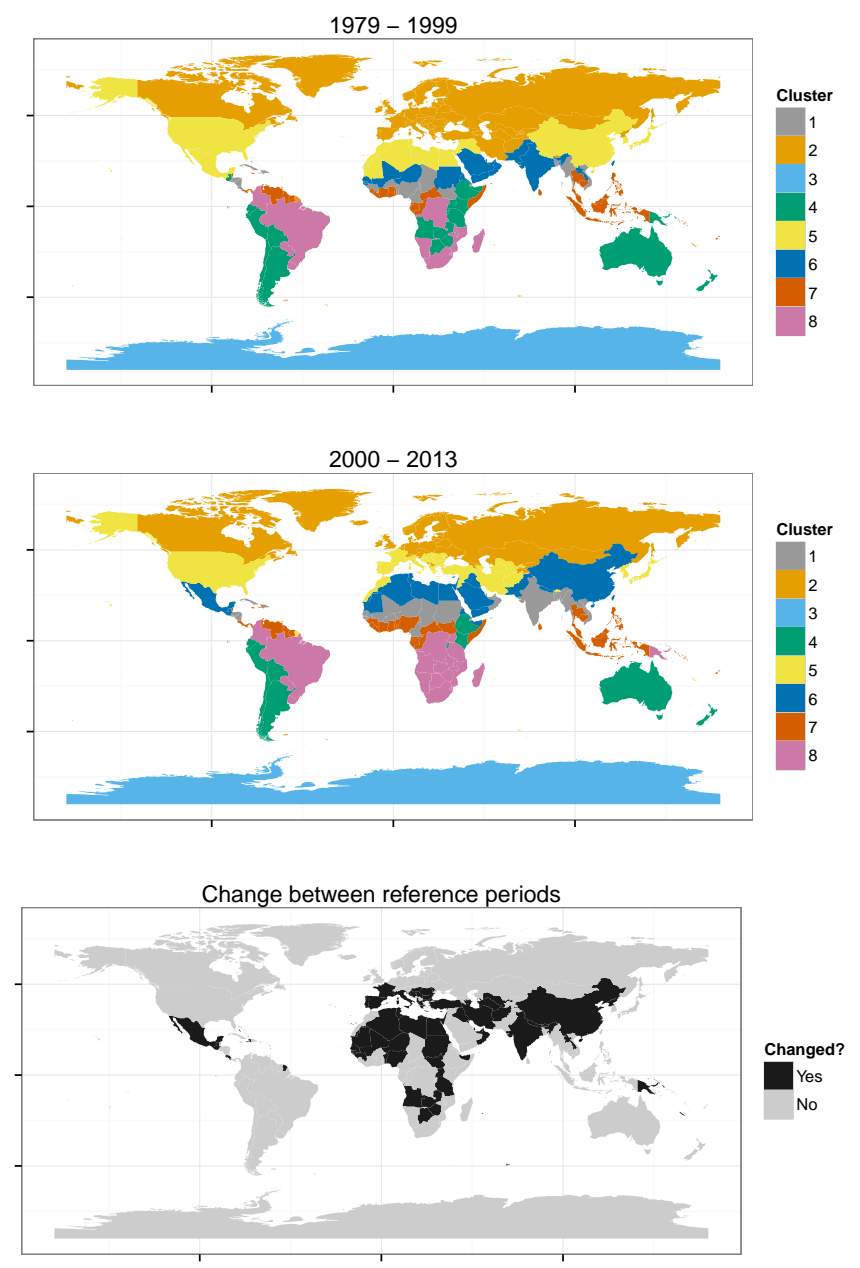

Figure 5. Countries and the clusters they were grouped into. The map at the top shows country clusters for the first reference period, and the map in the middle shows county clusters for the second. The map at the bottom indicates whether the cluster that a country was grouped into changed between both periods.

graphic areas or time periods in order to obtain more meaningful information.

It is also shown that heat index data can be used for studies on the country level, e.g., for classifying countries into heat index "climate zones". Such a country-level analysis is only a first example of possible ways of using these data. Examining them on a finer spatiotemporal scale and combining them with additional data could reveal more information and aid in analyzing, understanding and predicting the connection between heat index and various components of human systems.

The data are available for general use (Lee, 2014) and the scientific community is encouraged to take advantage of them in studies evaluating heat index, its distribution through space and time, and its connections to and influences on human systems. 
Acknowledgements. We thank the European Centre for Medium-Range Weather Forecasts for providing the original data. We also extend our thanks to all contributors to the several open source projects which were used in analyzing, manipulating and visualizing our data.

Edited by: D. Carlson

\section{References}

Alexander, L. V. and Arblaster, J. M.: Assessing trends in observed and modelled climate extremes over Australia in relation to future projections, Int. J. Climatol., 29, 417-435, doi:10.1002/joc.1730, 2009.

Anderson, G. B., Bell, M. L., and Peng, R. D.: Methods to Calculate the Heat Index as an Exposure Metric in Environmental Health Research, Environ. Health Persp., 121, 1111-1119, doi:10.1289/ehp.1206273, 2013.

Balk, D. and Yetman, G.: The global distribution of population: Evaluating the gains in resolution refinement, Tech. rep., Center for International Earth Science Information Network, Columbia University, Palisades, NY, http://sedac.ciesin.columbia.edu/ downloads/docs/gpw-v3/gpw3_documentation_final.pdf, 2004.

Balk, D., Yetman, G., and Sherbinin, A. D.: Construction of gridded population and poverty data sets from different data sources, in: Proceedings of European Forum for Geostatistics Conference, 12-20, European Forum for Geography and Statistics, Tallinn, Estonia, http://sedac.ciesin.columbia.edu/downloads/ docs/gpw-v3/balk_etal_geostatpaper_2010pdf-1.pdf, 2010.

Basara, J. B., Basara, H. G., Illston, B. G., and Crawford, K. C.: The Impact of the Urban Heat Island during an Intense Heat Wave in Oklahoma City, Advances in Meteorology, 2010, 1-10, doi:10.1155/2010/230365, 2010.

Beniston, M.: The 2003 heat wave in Europe: A shape of things to come? An analysis based on Swiss climatological data and model simulations, Geophys. Res. Lett., 31, L02202, doi:10.1029/2003GL018857, 2004.

Berrisford, P., Dee, D., Poli, P., Brugge, R., Fielding, K., Fuentes, M., Kållberg, P., Kobayashi, S., Uppala, S., and Simmons, A.: The ERA-Interim archive, version 2.0, Tech. Rep. 1, European Centre for Medium Range Weather Forecasts, Reading, http://old.ecmwf.int/publications/library/ecpublications/_pdf/ era/era_report_series/RS_1_v2.pdf, 2009.

Bivand, R. and Rundel, C.: rgeos: Interface to Geometry Engine - Open Source (GEOS), http://CRAN.R-project.org/package= rgeos, $r$ package version 0.3-8, 2014.

Burkart, K., Schneider, A., Breitner, S., Khan, M. H., Krämer, A., and Endlicher, W.: The effect of atmospheric thermal conditions and urban thermal pollution on all-cause and cardiovascular mortality in Bangladesh, Environ. Pollut., 159, 2035-2043, doi:10.1016/j.envpol.2011.02.005, 2011.

Calzadilla, A., Rehdanz, K., Betts, R., Falloon, P., Wiltshire, A., and Tol, R. S. J.: Climate change impacts on global agriculture, Tech. Rep. 1617, Kiel working paper, http://www.econstor.eu/handle/ 10419/32519, 2010.

Center for International Earth Science Information Network CIESIN - Columbia University; International Food Policy Research Institute - IFPRI; The World Bank; Centro Internacional de Agricultura Tropical - CIAT: Gridded Population of the World (GPW), Version 3, http://beta.sedac.ciesin.columbia.edu/ gpw, 2004.

Center for International Earth Science Information Network CIESIN - Columbia University; International Food Policy Research Institute - IFPRI; The World Bank; Centro Internacional de Agricultura Tropical - CIAT: Global Rural-Urban Mapping Project, Version 1 (GRUMPv1): Population Count Grid, http: //dx.doi.org/10.7927/H4VT1Q1H, 2011.

Dee, D. P., Uppala, S. M., Simmons, A. J., Berrisford, P., Poli, P., Kobayashi, S., Andrae, U., Balmaseda, M. A., Balsamo, G., Bauer, P., Bechtold, P., Beljaars, A. C. M., van de Berg, L., Bidlot, J., Bormann, N., Delsol, C., Dragani, R., Fuentes, M., Geer, A. J., Haimberger, L., Healy, S. B., Hersbach, H., Hólm, E. V., Isaksen, L., Kållberg, P., Köhler, M., Matricardi, M., McNally, A. P., Monge-Sanz, B. M., Morcrette, J.-J., Park, B.-K., Peubey, C., de Rosnay, P., Tavolato, C., Thépaut, J.-N., and Vitart, F.: The ERA-Interim reanalysis: configuration and performance of the data assimilation system, Q. J. Roy. Meteorol. Soc., 137, 553597, doi:10.1002/qj.828, 2011.

Diffenbaugh, N. S. and Ashfaq, M.: Intensification of hot extremes in the United States: INTENSIFICATION OF HOT EXTREMES, Geophys. Res. Lett., 37, doi:10.1029/2010GL043888, 2010.

Diffenbaugh, N. S. and Scherer, M.: Observational and model evidence of global emergence of permanent, unprecedented heat in the 20th and 21st centuries: A letter, Climatic Change, 107, 615624, doi:10.1007/s10584-011-0112-y, 2011.

El Morjani, Z. E. A., Ebener, S., Boos, J., Abdel Ghaffar, E., and Musani, A.: Modelling the spatial distribution of five natural hazards in the context of the WHO/EMRO Atlas of Disaster Risk as a step towards the reduction of the health impact related to disasters, Int. J. Health Geogr., 6, 8, doi:10.1186/1476-072X-6-8, 2007.

Everitt, B. and Hothorn, T.: A handbook of statistical analyses using R, CRC Press, Boca Raton, 2nd edn., 2010.

GRASS Development Team: Geographic Resources Analysis Support System (GRASS GIS) Software, Open Source Geospatial Foundation, USA, http://grass.osgeo.org, 2012.

Hartigan, J. A. and Wong, M. A.: Algorithm AS 136: A KMeans Clustering Algorithm, Applied Statistics, 28, 100-108, doi:10.2307/2346830, 1979.

Intergovernmental Panel on Climate Change (Ed.): Climate Change 2013 - The Physical Science Basis: Working Group I Contribution to the Fifth Assessment Report of the Intergovernmental Panel on Climate Change, Cambridge University Press, Cambridge, http://ebooks.cambridge.org/ref/id/ CBO9781107415324, 2014.

International Organization for Standardization: Hot environments - Estimation of the heat stress on working man, based on the WBGT-index (wet bulb globe temperature), Tech. Rep. 7423:1989, International Organization for Standardization, http://www.iso.org/iso/catalogue_detail.htm?csnumber= 13895, 2010.

Jendritzky, G., Schirmer, H., Menz, G., and Schmidt-Kessen, W.: Methode zur raumbezogenen Bewertung der thermischen Komponente im Bioklima des Menschen (Fortgeschriebenes KlimaMichel-Modell), Akademie für Raumforschung und Landesplanung, 114, 7-69, 1990. 
Kjellstrom, T., Kovats, R. S., Lloyd, S. J., Holt, T., and Tol, R. S. J.: The Direct Impact of Climate Change on Regional Labor Productivity, Arch. Environ. Occup. H., 64, 217-227, doi:10.1080/19338240903352776, 2009.

Kysely, J. and Kim, J.: Mortality during heat waves in South Korea, 1991 to 2005: How exceptional was the 1994 heat wave?, Climate Research, 38, 105-116, doi:10.3354/cr00775, 2009.

Lawrence, M. G.: The Relationship between Relative Humidity and the Dewpoint Temperature in Moist Air: A Simple Conversion and Applications, B. Am. Meteorol. Soc., 86, 225-233, doi:10.1175/BAMS-86-2-225, 2005.

Lee, D.: Heat index at $2 \mathrm{~m}$ above ground: A globally gridded dataset based on reanalysis data from 1979-2013, links to GeoTIFFs, http://doi.pangaea.de/10.1594/PANGAEA.841057, supplement to: Lee, Daniel (2014): Perceived temperature in the course of climate change: An analysis of global heat index from 1979-2013, submitted, 2014.

Mass, C. F., Ovens, D., Westrick, K., and Colle, B. A.: Does Increasing Horizontal Resolution Produce More Skillful Forecasts?, B. Am. Meteorol. Soc., 83, 407-430, doi:10.1175/15200477(2002)083<0407:DIHRPM>2.3.CO;2, 2002.

Meehl, G. A., Tebaldi, C., Walton, G., Easterling, D., and McDaniel, L.: Relative increase of record high maximum temperatures compared to record low minimum temperatures in the U.S., Geophys. Res. Lett., 36, L23701, 2009.

Murphy, R.: Relative humidity, http://www.erh.noaa.gov/bgm/ tables/rh.shtml (last access: August 2015), 2006.

National Institute for Occupational Safety and Health: Criteria for a Recommended Standard: Occupational Exposure to Hot Environments (Revised Criteria 1986), Tech. Rep. 86-113, National Institute for Occupational Safety and Health, http://www.cdc. gov/niosh/docs/86-113/, 1986.

National Weather Service: Heat Index Equation, http://www.wpc. ncep.noaa.gov/html/heatindex_equation.shtml (last access: August 2015), 2014a.

National Weather Service: Heat Safety, http://www.nws.noaa.gov/ os/heat/index.shtml (last access: August 2015), 2014b.

Oksanen, J., Blanchet, F. G., Kindt, R., Legendre, P., Minchin, P. R., O'Hara, R. B., Simpson, G. L., Solymos, P., Stevens, M. H. H., and Wagner, H.: vegan: Community Ecology Package, http://CRAN.R-project.org/package=vegan, $r$ package version 2.2-0, 2014.

Patterson, T. and Kelso, N. V.: Natural Earth, http://naturalearthdata. com (last access: August 2015), 2014.

Perry, A. G., Korenberg, M. J., Hall, G. G., and Moore, K. M.: Modeling and Syndromic Surveillance for Estimating WeatherInduced Heat-Related Illness, Journal of Environmental and Public Health, 2011, 1-10, doi:10.1155/2011/750236, 2011.
Poumadère, M., Mays, C., Le Mer, S., and Blong, R.: The 2003 Heat Wave in France: Dangerous Climate Change Here and Now, Risk Anal., 25, 1483-1494, doi:10.1111/j.1539-6924.2005.00694.x, 2005.

R Core Team: R: A Language and Environment for Statistical Computing, R Foundation for Statistical Computing, Vienna, Austria, http://www.R-project.org, 2014.

Rothfusz, L. P.: The heat index "equation" (or, more than you ever wanted to know about heat index), 1990.

Schär, C., Vidale, P. L., Lüthi, D., Frei, C., Häberli, C., Liniger, M. A., and Appenzeller, C.: The role of increasing temperature variability in European summer heatwaves, Nature, 427, 332336, doi:10.1038/nature02300, 2004.

Sherwood, S. C., Meyer, C. L., Allen, R. J., and Titchner, H. A.: Robust Tropospheric Warming Revealed by Iteratively Homogenized Radiosonde Data, J. Climate, 21, 5336-5352, doi:10.1175/2008JCLI2320.1, 2008.

Smith, T. M., Peterson, T. C., Lawrimore, J. H., and Reynolds, R. W.: New surface temperature analyses for climate monitoring: SURFACE TEMPERATURE ANALYSES, Geophys. Res. Lett., 32, L14712, doi:10.1029/2005GL023402, 2005.

South, A.: rworldmap: A New R package for Mapping Global Data, The R Journal, 3, 35-43, http://journal.r-project.org/archive/ 2011-1/RJournal_2011-1_South.pdf, 2011.

Steadman, R. G.: The Assessment of Sultriness. Part II: Effects of Wind, Extra Radiation and Barometric Pressure on Apparent Temperature, J. Appl. Meteorol., 18, 874-885, doi:10.1175/1520-0450(1979)018<0874:TAOSPI>2.0.CO;2, 1979.

Thorne, P. W. and Vose, R. S.: Reanalyses Suitable for Characterizing Long-Term Trends: Are They Really Achievable?, B. Am. Meteorol. Soc., 91, 353-361, doi:10.1175/2009BAMS2858.1, 2010.

Vose, R. S., Wuertz, D., Peterson, T. C., and Jones, P. D.: An intercomparison of trends in surface air temperature analyses at the global, hemispheric, and grid-box scale: INTERCOMPARISON OF TEMPERATURE ANALYSES, Geophys. Res. Lett., 32, doi:10.1029/2005GL023502, 2005.

Wickham, H.: ggplot2: elegant graphics for data analysis, Springer New York, http://had.co.nz/ggplot2/book, 2009. 